\title{
Regulatory Effects of the Saturated Fatty Acids 6:0 through 18:0 on Hepatic Low Density Lipoprotein Receptor Activity in the Hamster
}

\author{
Laura A. Woollett, David K. Spady, and John M. Dietschy \\ Department of Internal Medicine, University of Texas Southwestern Medical Center at Dallas, Dallas, Texas 75235
}

\begin{abstract}
The plasma concentration of cholesterol carried in low density lipoproteins is principally determined by the level of LDL re-

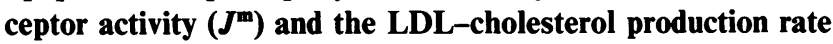
$\left(J_{t}\right)$ found in animals or man. This study delineates which saturated fatty acids alter $J^{\mathrm{m}}$ and $J_{\mathrm{t}}$ and so increase the plasma LDL-cholesterol level. $J^{\mathrm{m}}$ and $J_{t}$ were measured in vivo in hamsters fed a constant level of added dietary cholesterol $(0.12 \%)$ and triacylglycerol $(\mathbf{1 0 \%})$, where the triacylglycerol contained only a single saturated fatty acid varying in chain length from 6 to 18 carbon atoms. After feeding for $30 \mathrm{~d}$, the 12:0, 14:0, 16:0, and 18:0 fatty acids, but not the 6:0, 8:0, and 10:0 compounds, became significantly enriched in the liver total lipid fraction of the respective groups fed these fatty acids. However, only the 12:0, 14:0, and 16:0 fatty acids, but not the 6:0, 8:0, 10:0, and 18:0 compounds, suppressed $J^{\mathrm{m}}$, increased $J_{t}$, and essentially doubled plasma LDL-cholesterol concentrations. Neither the 16:0 nor 18:0 compound altered rates of cholesterol synthesis in the extrahepatic organs, and both lowered the hepatic total cholesterol pool. Thus, the different effects of the 16:0 and 18:0 fatty acids could not be attributed to a difference in cholesterol delivery to the liver. Since these changes in LDL kinetics took place without an apparent alteration in external sterol balance, the regulatory effects of the 12:0, 14:0, and 16:0 fatty acids presumably are mediated through some change in a putative intrahepatic regulatory pool of sterol in the liver. (J. Clin. Invest. 1992.89:1133-1141.) Key words: atherosclerosis • cholesterol esters • saturated fat
\end{abstract}

\section{Introduction}

In either the experimental animal or man, the steady-state concentration of cholesterol carried in low density lipoproteins is usually low when the dietary intake of cholesterol and triacylglycerol is minimal (1-5) (unpublished observations in cynomolgus monkey). In this situation where little lipid is reaching the liver in the chylomicron remnant, the rate at which LDL cholesterol is being produced and enters the plasma space is low, relative to the rate at which LDL can be removed from the plasma by receptor-dependent transport. In the hamster, for example, the LDL-cholesterol production rate $\left(J_{t}\right)^{1}$ is only about $150 \mu \mathrm{g} / \mathrm{h}$, while the maximal achievable rate of receptor-

Address correspondence and reprint requests to Dr. John M. Dietschy, Dept. of Internal Medicine, University of Texas Southwestern Medical Center at Dallas, 5323 Harry Hines Blvd., Dallas, TX 75235-8887.

Received for publication 26 August 1991 and in revised form 21 November 1991.

J. Clin. Invest.

(C) The American Society for Clinical Investigation, Inc.

0021-9738/92/04/1133/09 \$2.00

Volume 89, April 1992, 1133-1141 dependent removal $\left(J^{\mathrm{m}}\right)$ equals $\sim 700 \mu \mathrm{g} / \mathrm{h}(6,7)$. Similar relative rates for $J_{\mathrm{t}}$ and $J^{\mathrm{m}}$ are found in the rat $(\sim 100 \mathrm{vs} 600 \mu \mathrm{g} / \mathrm{h})$ and rabbit $(\sim 700$ vs $2,100 \mu \mathrm{g} / \mathrm{h})$ fed low-fat diets $(6,8,9)$. When increasing amounts of cholesterol alone are added to the diet, there is a dose-dependent increase in the level of cholesteryl esters in the liver, progressive suppression of LDL receptor activity, and small increases in the LDL-cholesterol production rate $(7,10)$. As a result of these changes, there are modest increases in the steady-state concentration of LDL-cholesterol in the plasma (10).

The addition of triacylglycerol to such cholesterol-containing diets often has more dramatic effects on the plasma cholesterol level and the parameters of LDL metabolism that determine these levels. Generally, triacylglycerol containing saturated fatty acids lowers the concentration of hepatic cholesteryl esters, further suppresses receptor activity, significantly increases the LDL-cholesterol production rate, and, as a consequence of these events, markedly raises the plasma LDL-cholesterol level (10-12). In contrast, triacylglycerol that contains predominantly unsaturated fatty acids often elevates the hepatic stores of sterol esters and restores receptor-dependent transport, but has little effect on LDL-cholesterol production rates $(10,12)$. The net effect of these changes is usually a smallto-modest decrease in the plasma LDL-cholesterol level (12). These regulatory properties of saturated and unsaturated fatty acids are dose dependent and algebraically additive, i.e., mixtures of these different lipids result in intermediate and predictable alterations in $J^{\mathrm{m}}, J_{t}$, and the plasma cholesterol concentration (12). However, it is also apparent that not all saturated and unsaturated fatty acids produce similar results. For example, feeding hydrogenated coconut oil, which is rich in the 12:0 and 14:0 saturated fatty acids, markedly alters $J^{\mathrm{m}}, J_{t}$, and the plasma cholesterol concentration, while medium chain triglyceride oil, which contains predominantly the 8:0 and 10:0 saturated fatty acids, has virtually no effect on these parameters (7). Similarly, there is evidence suggesting that different unsaturated fatty acids have quantitatively different effects on LDL transport and formation (unpublished observation from this laboratory).

Even though these general features of how dietary cholesterol and triacylglycerol alter plasma cholesterol levels have been described in the experimental animal and in man, little is known about how these regulatory events are actually articulated within the liver. While LDL receptor activity apparently is controlled by sterol regulatory elements (13-16), there is virtually no information on how the nucleus actually senses the cholesterol content of the liver cell. Furthermore, it is not

1. Abbreviations used in this paper: $J^{\mathrm{m}}$, maximal achievable rate of receptor-dependent LDL transport; $J_{t}$, LDL-cholesterol production rate; $K_{m}$, the concentration of plasma LDL-cholesterol necessary to achieve half the velocity of $\mathrm{J}^{\mathrm{m}} ; \mathrm{P}$, the proportionality constant for receptor-independent LDL transport in an organ or the whole animal. 
known whether dietary triacylglycerol acts extrahepatically to change net cholesterol balance across the liver, or intrahepatically to alter the relationship between the putative regulatory pool of sterol and the appropriate genes. This situation is further complicated by the fact that the fatty acids of dietary triacylglycerols may vary markedly in their physical, chemical, and regulatory properties. For example, $(a)$ saturated fatty acids may vary in the length of their hydrocarbon chain; $(b)$ when chain-length is kept constant, the fatty acids may contain varying numbers of double bonds; $(c)$ when chain length and number of double bonds are kept constant, the double bond may exist in either the cis or trans configuration; and $(d)$ fatty acids may occupy different positions on the triacylglycerol molecule, and so possibly be delivered to different tissues during the absorptive process.

In order to begin to understand these complex relationships, the present studies were undertaken to specifically delineate the effect of fatty acid chain length on the regulatory activity of saturated lipids on the parameters of LDL metabolism. Under experimental circumstances, where total dietary cholesterol and triacylglycerol were kept constant, hamsters were fed pure triacylglycerols containing only a single saturated fatty acid that varied in chain length from 6 to 18 carbon atoms. The appearance of each of these fatty acids in the liver and extrahepatic tissues was followed, and the effect of the different lipids on cholesterol synthesis in vivo in the major body compartments was quantified. Finally, the plasma LDL-cholesterol concentration, the maximal achievable rate of receptor-dependent transport, and the LDL-cholesterol production rates were measured in each experimental group. These studies demonstrate that only a few of the saturated fatty acids alter parameters of LDL metabolism, and these regulatory effects appear to be articulated within the liver cell itself.

\section{Methods}

Animals and diets. Sexually mature male Golden Syrian hamsters $\sim 10$ wk old (Charles River Breeding Laboratories, Inc., Wilmington, MA) were housed in colony cages for $2 \mathrm{wk}$ before the experiments were started. Animals were subjected to $12 \mathrm{~h}$ of light and $12 \mathrm{~h}$ of darkness before, and during, the experiments, and measurements were made during the middark phase of the cycle. Four types of diets were employed in these studies (10): (a) plain diet which consisted of ground Wayne Lab Blox (Allied Mills, Chicago, IL) containing $0.02 \%$ (wt/wt) cholesterol and $5.0 \%$ total lipids; $(b)$ plain diet to which was added $0.12 \%$ pure cholesterol dissolved in ethanol and then dried; $(c)$ control diet made from this same ground diet and containing $0.12 \%$ added cholesterol and $10 \%$ added olive oil; and $(d)$ experimental diets that contained the additions of $0.12 \%$ cholesterol, $10 \%$ olive oil, and $10 \%$ triacylglycerol that was made up of a single saturated fatty acid varying in chain length from 6:0 to 18:0 (Sigma Chemical Co., St. Louis, MO and Fluka Chemika, A. G., Buchs, Switzerland). In several different experiments, the intake of the diet containing the 10:0 fatty acid was poor, apparently because of the pungent odor of this particular triacylglycerol. Therefore, the experimental diet for this compound was made up by dissolving the pure triacylglycerol in medium chain triglyceride oil, and then adding this to the control diet. Thus, this particular experimental diet contained $0.12 \%$ cholesterol, $10 \%$ olive oil, $10 \%$ triacylglycerol containing the 10:0 fatty acid, and $7.5 \%$ of triacylglycerol containing the 8:0 compound. It should be noted that this additional amount of 8:0 fatty acid is biologically neutral with respect to LDL metabolism. In all studies, groups of animals of essentially identical initial weights were fed these various diets ad lib. for $30 \mathrm{~d}$, at which time a variety of measurements were made.
Dietary lipid absorption. Net lipid absorption was quantified by measuring the amounts of dietary lipid that were eaten, and the amounts that were excreted in the feces. The amount of food consumed by each experimental group of animals was measured over a 1-wk interval. During this same week, two 24-h fecal collections were also obtained. Aliquots of the diet and feces were dried overnight in an oven and ground, and a total lipid extraction was carried out. After evaporation of the solvent, the amount of lipid in the diet and feces was determined gravimetrically. Net lipid absorption was calculated as the difference between dietary intake and fecal excretion (gram/day per animal).

Tissue fatty acid abundance. Adipose tissue, skeletal muscle, and liver were extracted with Folch reagent, and the samples were methyl esterified (17). These methyl ester derivatives were then injected into a $30-\mathrm{m}$ long, fused silica capillary column coated with a $0.25-\mu \mathrm{m}$ film of Supelcowax 10 , and run at 175 to $220^{\circ} \mathrm{C}$. The fatty acid abundance in the various major lipid classes was also determined after these classes were first separated on thin layer chromatography plates. The plates used were SIL G-25 (Brinkmann Instrs. Inc., Westbury, NY) and these were developed in hexane/diethyl ether/glacial acetic acid (90:21:2, $\mathrm{vol} / \mathrm{vol})$. Samples were extracted from the stationary phase directly into the methanol/benzene phase used for methyl esterification.

Tissue cholesterol concentrations. Plasma LDL-cholesterol concentrations were determined by simultaneously centrifuging plasma samples at the densities of 1.020 and $1.063 \mathrm{~g} / \mathrm{ml}(10)$. Aliquots of liver were saponified and the total cholesterol content was quantified $(10,18)$.

Lipoprotein preparations. Hamster LDL was isolated from donor animals in the density range of $1.020-1.055 \mathrm{~g} / \mathrm{ml}$ by preparative ultracentrifugation $(10,11)$. The donor animals had been maintained on a low-cholesterol, low-fat diet before harvesting the blood. The LDL was then labeled with either ${ }^{125}$ I tyramine cellobiose $(10,19)$ or ${ }^{131} I(10,20$, 21 ), and used within $24 \mathrm{~h}$ of preparation. All samples were filtered through a $0.45-\mu \mathrm{m}$ Millipore filter immediately before injection into recipient animals.

In vivo $L D L$ clearance rates. Rates of tissue $L D L$ clearance were determined in vivo using a primed-continuous infusion of ${ }^{125}$ I tyramine cellobiose-labeled LDL $(10,22,23) .10 \mathrm{~min}$ before termination of the 4-h infusion period, a bolus of ${ }^{131} \mathrm{I}$-labeled LDL was administered to each of the animals. The animals were then killed at $4 \mathrm{~h}$ by exsanguination through the abdominal aorta. The liver was removed and the remaining carcass was frozen in liquid nitrogen and ground to a fine powder. Aliquots were then assayed for radioactivity. Clearance rates were determined by subtracting the tissue space of LDL at $10 \mathrm{~min}\left({ }^{131} \mathrm{I}\right.$ dpm per gram of tissue divided by the ${ }^{131} \mathrm{I} \mathrm{dpm}$ per microliter of plasma) from the tissue space of LDL at $4 \mathrm{~h}\left({ }^{125} \mathrm{I} \mathrm{dpm}\right.$ per gram of tissue divided by the ${ }^{125} \mathrm{I} \mathrm{dpm}$ per microliter of plasma). These clearance rates were calculated as the microliter of plasma cleared of its LDL content/ hour per gram of tissue (microliter/hour per gram). In addition, these rates were multiplied by the whole liver and carcass weights in order to calculate LDL clearance by these two whole tissues (microliter/hour per tissue).

In vivo $L D L$-cholesterol uptake rates. From these $L D L$ clearance rates, uptake rates of $L D L$ cholesterol were determined. These uptake rates were expressed as the absolute mass of LDL cholesterol that was taken up per hour per gram of tissue (microgram/hour per gram) and were calculated by multiplying the clearance rates of LDL (microliter/ hour per gram) by the plasma LDL-cholesterol concentration (micro$\mathrm{gram} / \mathrm{microliter}$ ). These rates, in turn, were multiplied by the whole liver and carcass weights to give the LDL-cholesterol uptake rates per whole tissue (microgram/hour per tissue), and these values were then normalized to a constant body weight of $100 \mathrm{~g}$.

In vivo LDL-cholesterol production rates. Because these studies were performed during steady-state conditions where there was no detectable change in the plasma LDL-cholesterol concentration, the sum of the LDL-cholesterol uptake rates in all of the tissues of the animal must equal the rate of LDL-cholesterol production. Thus, LDL-cholesterol production rates were calculated by summing the LDL-choles- 
terol uptake rates in the liver and carcass, and these values were expressed as the microgram of LDL-cholesterol produced per hour per whole animal (microgram/hour per animal). These rates were then normalized to a constant body weight of $100 \mathrm{~g}$.

In vivo hepatic sterol synthesis. Animals were killed by exsanguination through the abdominal aorta $1 \mathrm{~h}$ after the intravenous administration of $\left.{ }^{3} \mathrm{H}\right]$ water $(100 \mathrm{mCi})$. Liver, small intestine, and the entire remaining carcass were then saponified, and digitonin precipitable sterols were isolated, as previously described (24-26). The rates of sterol synthesis in vivo are expressed as the nanomoles of $\left[{ }^{3} \mathrm{H}\right]$ water incorporated into digitonin precipitable sterols per hour per whole liver, small intestine, carcass, and whole animal (nanomoles/hour per organ or animal).

Calculations. The steady-state concentration of LDL cholesterol is known to be determined by four separate parameters of LDL metabolism (27). The rate at which LDL cholesterol is taken up by a particular organ or by all of the tissues of the body $\left(J_{t}\right)$ is equal to the sum of the rates of uptake by the receptor-dependent $\left(J_{d}\right)$ and receptor-independent $\left(J_{\mathrm{i}}\right)$ transport processes in that organ or whole animal. Since $J_{\mathrm{d}}$ equals $\left(J^{\mathrm{m}} \mathrm{C}_{1}\right) /\left(K_{\mathrm{m}}+\mathrm{C}_{1}\right)$ and $J_{\mathrm{i}}$ equals $\mathrm{PC}_{1}$, it follows that $J_{\mathrm{t}}$ for any organ or for the whole animal can be calculated from the following expression $(8,27)$ :

$J_{\mathrm{t}}=\frac{J^{\mathrm{m}} \mathrm{C}_{1}+\mathrm{PC}_{1} K_{\mathrm{m}}+\mathrm{PC}_{1}^{2}}{K_{\mathrm{m}}+\mathrm{C}_{1}}$

The parameter $J^{\mathrm{m}}$ is the maximal receptor-dependent transport velocity (a reflection of receptor number); $K_{\mathrm{m}}$ is the plasma concentration of LDL-cholesterol at which one half of this maximal transport rate is achieved (a reflection of receptor affinity); $C_{1}$ is the concentration of plasma LDL cholesterol in a given animal; and $\mathrm{P}$ is the proportionality constant for LDL transport by way of the receptor-independent pathway. The relationship between $J_{t}$ and $C_{1}$ can be defined for a particular organ like the liver or the whole animal. Furthermore, in the latter case, this equation can be rearranged to give an expression that describes how the plasma LDL-cholesterol concentration will change in the whole animal given any alteration in receptor number $\left(J^{\mathrm{m}}\right)$ or LDLcholesterol production, since, in the steady state, the rate of LDL-cholesterol removal from the plasma space $\left(J_{v}\right)$ must equal the rate of entry into the plasma. This second expression is as follows:

$\mathrm{C}_{1}=\frac{\left(J_{\mathrm{t}}-J^{\mathrm{m}}-\mathrm{P} K_{\mathrm{m}}\right)+\sqrt{\left(J_{\mathrm{t}}-J^{\mathrm{m}}-\mathrm{P} K_{\mathrm{m}}\right)^{2}+4 \mathrm{P} K_{\mathrm{m}} J_{\mathrm{t}}}}{2 \mathrm{P}}$

The specific values for each of these parameters in the liver and whole animal were determined in a group of hamsters fed plain diet, and these are presented in Table III. In each experiment, changes in receptor activity $\left(J^{\mathrm{m}}\right)$ and production rate $\left(J_{\mathrm{t}}\right)$ are given relative to these absolute values, i.e., they are expressed as a percentage of the respective values found in simultaneously run animals receiving the plain diet.

Where appropriate, mean values \pm 1 SEM are given. The Student's $t$ test was used $(P<0.05)$ to compare two treatments $(28)$.

\section{Results}

These studies were specifically undertaken using triacylglycerols that contained only a single saturated fatty acid, rather than mixtures of fatty acids, so that the metabolic and regulatory effects of each compound could be more accurately identified. However, it was anticipated that the triacylglycerols containing the longer chain-length fatty acids would be poorly absorbed, and this proved to be the case in preliminary experiments where significant steatorrhea was identified in animals fed triacylglycerols containing the 16:0 and 18:0 fatty acids. After testing various combinations of diets, however, it was found that this steatorrhea was minimized when the pure triacylglycerols were mixed with an equal weight of olive oil. In addition to these triacylglycerols, a constant level of cholesterol was also added to the diets to partially suppress hepatic receptor-dependent transport and so make the animals maximally sensitive to the regulatory action of saturated fatty acids $(10,12)$.

Thus, on the basis of these preliminary investigations, the control diet contained a constant level of added cholesterol $(0.12 \%)$ and olive oil $(10 \%)$, and each experimental diet contained an additional $10 \%$ of one of the triacylglycerols made up of the fatty acids 6:0 through 18:0. The absorption and growth characteristics of hamsters fed these diets for $30 \mathrm{~d}$ are shown in Fig. 1. The animals fed the control diet absorbed an average of $1.4 \mathrm{~g}$ of lipid per day, while those receiving the seven different experimental diets all absorbed $\sim 2.5 \mathrm{~g}$ of lipid per day $(A)$. At the beginning of the feeding period, the animals had been distributed so that the mean weights of each experimental group were the same. After $30 \mathrm{~d}$ of eating each diet, all groups of animals had gained essentially identical amounts of weight and averaged $\sim 150 \mathrm{~g}(B)$. Thus, these studies suggested that under the conditions of these experiments the various saturated fatty acids were being well absorbed and utilized by the animals.

To further confirm that the specific fatty acids being fed reached the liver and other tissues, aliquots of several organs were removed from animals fed the eight different diets for 30 $\mathrm{d}$, and the distribution of specific fatty acids in the total lipid extracts of these tissues was determined. Since a large fraction of dietary fatty acids is delivered by the chylomicrons directly to storage sites in the peripheral adipose tissue, the distribution of fatty acids in this tissue was examined first. As shown in Table I, in animals fed the control diet alone the predominant species in adipose tissue lipids were the 18:1 (51.0\%), 16:0 $(20.1 \%)$, and $18: 2(16.2 \%)$ fatty acids. There were no detectable fatty acids of chain length shorter than 12:0. This was also true in the animals fed the experimental diets containing the 6:0, 8:0, and 10:0 fatty acids; furthermore, in these same three groups there was no change in relative abundance of the longer chain-length fatty acids. However, when the 12:0, 14:0, 16:0, and 18:0 fatty acids were in the diets, there was a significant increase in the relative abundance of each of these lipids in the

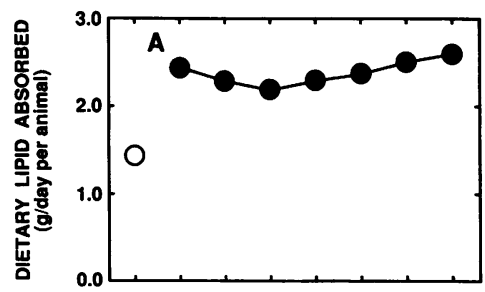

Figure 1. Dietary lipid absorption and weight gain in animals fed the control diet and diets containing specific triacylglycerols. The control diet contained $0.12 \%$ cholesterol and $10 \%$ olive oil, while the experimen-

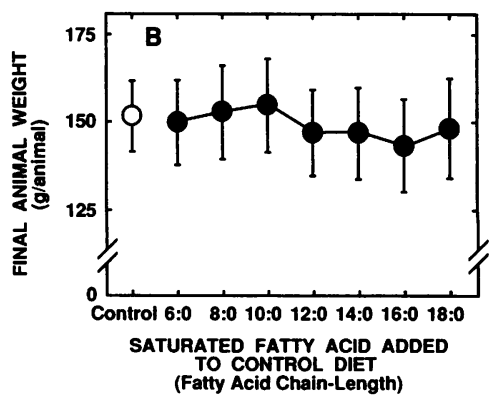
tal diets contained an additional $10 \%$ of triacylglycerol made up of the fatty acids $6: 0$ through 18:0. After a 23-d feeding period, groups of six animals receiving each diet were placed in metabolic cages, and the quantity of lipid eaten in the diet and excreted in the feces was measured over the

next $7 \mathrm{~d}$. $A$ shows the mean levels of net lipid absorption calculated from these data in the various experimental groups. $B$ shows the final animal weights after being fed each of these diets for $30 \mathrm{~d}$. Mean values \pm 1 SEM for six animals in each group are shown. 
Table I. Relative Abundance of Each Fatty Acid in the Lipids of Adipose Tissue and Liver in Animals Fed Triacylglycerols Containing a Single Saturated Fatty Acid

\begin{tabular}{|c|c|c|c|c|c|c|}
\hline \multirow{2}{*}{$\begin{array}{l}\text { Saturated } \\
\text { fatty acid } \\
\text { added to } \\
\text { control diet }\end{array}$} & \multicolumn{6}{|c|}{ Relative abundance of each fatty acid (\% of total mass) } \\
\hline & 12:0 & 14:0 & $16: 0$ & $18: 0$ & 18:1 & $18: 2$ \\
\hline \multicolumn{7}{|c|}{ A Adipose tissue } \\
\hline Control & $<0.1$ & $1.0 \pm 0.1$ & $20.1 \pm 0.3$ & $2.7 \pm 0.1$ & $51.0 \pm 0.8$ & $16.2 \pm 0.5$ \\
\hline 6,8, or $10: 0$ & $<0.1$ & $1.0 \pm 0.1$ & $20.3 \pm 0.4$ & $2.8 \pm 0.1$ & $52.2 \pm 0.6$ & $15.0 \pm 0.2$ \\
\hline $12: 0$ & $17.0 \pm 1.6^{*}$ & $2.4 \pm 0.1^{*}$ & $17.2 \pm 0.5^{*}$ & $2.0 \pm 0.1^{*}$ & $41.5 \pm 1.1^{*}$ & $12.7 \pm 0.4^{*}$ \\
\hline $14: 0$ & $<0.1$ & $23.7 \pm 1.5^{*}$ & $15.6 \pm 0.6^{*}$ & $1.8 \pm 0.1^{*}$ & $40.3 \pm 0.6^{*}$ & $11.9 \pm 0.5^{*}$ \\
\hline $16: 0$ & $<0.1$ & $1.9 \pm 0.1^{*}$ & $33.0 \pm 0.6^{*}$ & $2.4 \pm 0.1$ & $42.0 \pm 0.6^{*}$ & $13.1 \pm 0.4^{*}$ \\
\hline $18: 0$ & $<0.1$ & $1.0 \pm 0.1$ & $17.7 \pm 0.4$ & $6.4 \pm 0.3^{*}$ & $51.7 \pm 0.8$ & $15.5 \pm 0.2$ \\
\hline \multicolumn{7}{|l|}{ B Liver } \\
\hline Control & $<0.1$ & $0.5 \pm 0.1$ & $16.7 \pm 0.5$ & $12.2 \pm 0.3$ & $38.7 \pm 0.8$ & $16.9 \pm 0.3$ \\
\hline 6,8, or $10: 0$ & $<0.1$ & $0.3 \pm 0.1$ & $16.8 \pm 0.7$ & $13.3 \pm 0.5$ & $37.3 \pm 0.6$ & $16.3 \pm 0.4$ \\
\hline $12: 0$ & $1.1 \pm .1^{*}$ & $1.7 \pm 0.2^{*}$ & $22.3 \pm 0.6^{*}$ & $11.3 \pm 0.7$ & $32.2 \pm 1.4^{*}$ & $19.2 \pm 0.6^{*}$ \\
\hline $14: 0$ & $<0.1$ & $5.0 \pm 0.4^{*}$ & $19.6 \pm 0.4^{*}$ & $13.0 \pm 0.5$ & $32.3 \pm 0.9^{*}$ & $17.7 \pm 0.7$ \\
\hline $16: 0$ & $<0.1$ & $0.5 \pm 0.2$ & $25.0 \pm 0.6^{*}$ & $13.8 \pm 0.5$ & $29.4 \pm 0.9^{*}$ & $17.1 \pm 0.3$ \\
\hline $18: 0$ & $<0.1$ & $0.3 \pm 0.1$ & $18.3 \pm 0.8$ & $19.6 \pm 0.9^{*}$ & $26.0 \pm 1.5^{*}$ & $18.4 \pm 0.5$ \\
\hline
\end{tabular}

For $30 \mathrm{~d}$, groups of animals were fed either the control diet alone or the control diet to which was added $10 \%$ triacylglycerol that contained one of the saturated fatty acids 6:0 through 18:0. At the end of this feeding period the relative abundance of the fatty acids 12:0, 14:0, 16:0, 18:0, 18:1, and 18:2 in the total lipid extracts of adipose tissue and liver was determined. These 6 fatty acids accounted for $>90 \%$ of the fatty acids in the adipose tissue extracts, and $\sim 85 \%$ of the fatty acids in the liver extracts. Each value equals the mean \pm 1 SEM for 6 animals. ${ }^{*}$ Value is significantly different $(P<0.05)$ from the control value.

respective groups. Thus, feeding the $12: 0$ compound increased the abundance of this fatty acids from $<0.1 \%$ in the control group to $17.0 \%$, and feeding the $14: 0,16: 0$, and 18:0 fatty acids also significantly increased the amounts of each of these respective acids in the adipose tissue. Notably, there were no increases in the relative abundance of the 18:1 and 18:2 fatty acids with the feeding of any of the saturated fatty acids. While not shown in Table I, similar distributions and relative enrichment were found in the lipids extracted from striated muscle.

These dietary lipids also reached the liver, carried, presumably, in chylomicron remnants or as fatty acids bound to albumin. As also shown in Table I, the predominant fatty acids in the livers of the control animals were $18: 1$ (38.7\%), 18:2 (16.9\%), 16:0 (16.7\%), and 18:0 (12:2\%). There were no signifcant changes in this distribution pattern when the animals were fed the 6:0, 8:0, and 10:0 fatty acids, nor were these shorter chain-length compounds detected. However, the hepatic lipids became significantly enriched with the 12:0,14:0,16:0, and 18:0 compounds when each of these respective acids was fed. There were two other notable findings in this study. First, not only was the relative abundance of the 16:0 compound increased by feeding the $16: 0$ fatty acid, but the level of this fatty acid was also significantly increased by feeding the $12: 0$ and 14:0, but not the 18:0, compounds. This finding was not observed in adipose tissue, and presumably reflects the ability of the hepatocyte to elongate the aliphatic chain of the $12: 0$ and 14:0 fatty acids. Second, even though the abundance of the 18:0 compound was significantly increased by feeding the 18:0 fatty acid, there was no alteration in the relative abundance of the 18:1 and 18:2 compounds. Thus, these data on enrichment of the fatty acid pools in the adipose, muscle, and hepatic tissues with dietary lipids, coupled with those for net lipid absorption and weight gain (Fig. 1), indicated that each of the fatty acids was well absorbed from the experimental diets and reached the target tissues.

To further elucidate where in the hepatic lipids these changes in fatty acid composition occurred, the total lipid extracts were next separated into triacylglycerols, cholesteryl esters, and phospholipids, and the relative abundance of the fatty acids in each of these classes was then quantified. As shown in Table II, in the animals fed the control diet the major fatty acids in hepatic triacylglycerols were the 18:1 (34.4\%) and 16:0 (28.1\%) compounds $(A)$. There were no significant amounts of fatty acids with a chain length of 12 carbon atoms or less. Feeding the 14:0,16:0, and 18:0 fatty acids increased the mean levels of these respective compounds in this hepatic triacylglycerol fraction, but these differences did not achieve statistical significance. Thus, in general, the abundance of different fatty acids in the triacylglycerols of the liver was relatively insensitive to the abundance of these fatty acids in the diet. This was not true of the cholesteryl ester fraction, however, where the major fatty acid esterified to cholesterol in the control animals was the $18: 1(67.2 \%)$ compound. The abundance of the $14: 0,16: 0$, and 18:0 compounds esterified to cholesterol became significantly elevated after the feeding of these respective fatty acids $(B)$. Furthermore, as found in the total lipid extracts from the liver, the relative abundance of the 16:0 fatty acid was increased with the feeding of the 12:0 and 14:0, but not the $18: 0$, fatty acids, as well as by feeding of the 16:0 compound. Like the triacylglycerol fraction, there was little change in the relative abundance of the fatty acids incorporated into the hepatic phospholipid fraction $(C)$. A small, but significant, increase in the abundance of the 16:0 fatty acid was induced by feeding this compound; otherwise the relative abundance of the different fatty acids remained remarkably constant, regardless of what was fed in the diet. 
Table II. Relative Abundance of Each Fatty Acid in Triacylglycerols, Cholesteryl Esters and Phospholipids Isolated from the Total Lipid Extracts of Livers in Animals Fed Triacylglycerols Containing a Single Saturated Fatty Acid

\begin{tabular}{|c|c|c|c|c|c|}
\hline \multirow{2}{*}{$\begin{array}{c}\text { Saturated } \\
\text { fatty acid added } \\
\text { to control diet }\end{array}$} & \multicolumn{5}{|c|}{ Relative abundance of each fatty acid (\% of total mass) } \\
\hline & 14:0 & $16: 0$ & 18:0 & $18: 1$ & $18: 2$ \\
\hline \multicolumn{6}{|l|}{ A Triacylglycerols } \\
\hline Control & $1.1 \pm 0.4$ & $28.1 \pm 1.8$ & $8.1 \pm 2.2$ & $34.4 \pm 4.7$ & $6.0 \pm 1.2$ \\
\hline 6,8 , or $10: 0$ & $0.7 \pm 0.3$ & $26.8 \pm 0.8$ & $7.6 \pm 0.7$ & $41.2 \pm 3.3$ & $5.6 \pm 0.6$ \\
\hline $12: 0$ & $2.8 \pm 1.1$ & $25.9 \pm 1.7$ & $5.6 \pm 1.6$ & $40.1 \pm 3.6$ & $6.7 \pm 1.0$ \\
\hline $14: 0$ & $2.2 \pm 1.2$ & $24.0 \pm 4.2$ & $5.4 \pm 0.5$ & $39.7 \pm 3.3$ & $7.2 \pm 1.6$ \\
\hline $16: 0$ & $0.4 \pm 0.2$ & $33.1 \pm 4.4$ & $7.1 \pm 1.1$ & $40.8 \pm 3.8$ & $6.2 \pm 0.7$ \\
\hline $18: 0$ & $1.2 \pm 0.8$ & $29.4 \pm 2.1$ & $13.2 \pm 3.1$ & $37.2 \pm 5.1$ & $5.5 \pm 1.1$ \\
\hline \multicolumn{6}{|c|}{ B Cholesteryl esters } \\
\hline Control & $0.2 \pm 0.1$ & $5.9 \pm 0.3$ & $3.7 \pm 0.1$ & $67.2 \pm 3.1$ & $6.4 \pm 0.7$ \\
\hline 6,8 , or $10: 0$ & $0.2 \pm 0.1$ & $6.1 \pm 0.4$ & $4.1 \pm 0.3$ & $71.5 \pm 0.8$ & $6.6 \pm 0.4$ \\
\hline $12: 0$ & $1.3 \pm 0.4$ & $9.7 \pm 0.8^{*}$ & $3.3 \pm 0.5$ & $61.7 \pm 0.9$ & $8.9 \pm 0.8$ \\
\hline $14: 0$ & $4.7 \pm 1.4^{*}$ & $9.1 \pm 0.4^{*}$ & $4.1 \pm 0.5$ & $59.5 \pm 0.7$ & $8.0 \pm 1.0$ \\
\hline $16: 0$ & $<0.1$ & $14.8 \pm 0.7^{*}$ & $5.7 \pm 0.6^{*}$ & $57.6 \pm 2.4$ & $8.0 \pm 1.2$ \\
\hline $18: 0$ & $<0.1$ & $6.4 \pm 0.5$ & $20.4 \pm 5.3^{*}$ & $51.9 \pm 6.3$ & $6.1 \pm 1.1$ \\
\hline \multicolumn{6}{|l|}{ C Phospholipids } \\
\hline Control & $<0.1$ & $27.0 \pm 1.6$ & $26.1 \pm 1.4$ & $16.7 \pm 0.7$ & $12.0 \pm 1.4$ \\
\hline 6,8 , or $10: 0$ & $<0.1$ & $25.3 \pm 3.3$ & $24.9 \pm 3.2$ & $15.7 \pm 2.4$ & $13.9 \pm 1.5$ \\
\hline $12: 0$ & $<0.1$ & $32.2 \pm 2.3$ & $21.0 \pm 1.9$ & $14.7 \pm 1.1$ & $12.1 \pm 2.0$ \\
\hline $14: 0$ & $<0.1$ & $30.8 \pm 1.3$ & $27.2 \pm 1.0$ & $14.2 \pm 0.4$ & $13.7 \pm 1.7$ \\
\hline $16: 0$ & $<0.1$ & $32.4 \pm 1.4^{*}$ & $25.1 \pm 1.9$ & $12.8 \pm 0.3^{*}$ & $12.9 \pm 1.7$ \\
\hline $18: 0$ & $<0.1$ & $26.3 \pm 1.4$ & $26.2 \pm 3.0$ & $20.3 \pm 5.2$ & $10.6 \pm 2.6$ \\
\hline
\end{tabular}

Aliquots of the total lipid extracts from the livers of the animals described in Table I were separated into triacylglycerols, cholesteryl esters, and phospholipids. The relative abundance of the fatty acids 14:0, 16:0, 18:0, 18:1, and 18:2 in each of these fractions was then determined. These 5 fatty acids accounted for approximately $80-85 \%$ of the fatty acids in the extracts. Each value equals the mean \pm 1 SEM for 6 animals. ${ }^{*}$ Value is significantly different $(P<0.05)$ from the control value.

Having established that these various dietary fatty acids reached the peripheral adipose and muscle tissues as well as the liver, the effect of these lipids on the major parameters of LDL metabolism was next investigated. First, however, it was necessary to define the absolute magnitude of maximal receptor-de- pendent LDL-cholesterol transport $\left(\mathrm{J}^{\mathrm{m}}\right)$ in the liver, and the LDL-cholesterol production rate $\left(J_{t}\right)$ in animals fed the control diet used in these experiments. As outlined in Table III, in hamsters fed plain ground diet with no lipid additives, $J_{\mathrm{t}}$ was low $(166 \mu \mathrm{g} / \mathrm{h})$ and $J^{\mathrm{m}}$ was high $(653 \mu \mathrm{g} / \mathrm{h})$, so that the mean

Table III. Hepatic Cholesterol Concentration, Maximal LDL-cholesterol Transport and the LDL-cholesterol Production Rate in Animals Fed Plain Diet or Diets Containing Cholesterol and Olive Oil

\begin{tabular}{|c|c|c|c|c|}
\hline Diet group & $\begin{array}{c}\text { Plasma } \\
\text { LDL-cholesterol } \\
\text { concentration }\end{array}$ & $\begin{array}{l}\text { Hepatic cholesterol } \\
\text { concentration }\end{array}$ & $\begin{array}{l}\text { Maximal hepatic } \\
\text { receptor-dependent LDL- } \\
\text { cholesterol transport }\left(J^{\mathrm{m}}\right)\end{array}$ & $\begin{array}{l}\text { LDL-cholesterol } \\
\text { production rate } \\
\left(J_{t}\right)\end{array}$ \\
\hline & $m g / d l$ & $m g / g$ & $\mu g / h$ per $100 \mathrm{~g}$ & $\mu g / h$ per $100 \mathrm{~g}$ \\
\hline Plain diet & $25.0 \pm 2$ & $2.4 \pm 0.3$ & $653 \pm 26$ & $166 \pm 12$ \\
\hline Plus cholesterol $(0.12 \%)$ & $59.0 \pm 5^{*}$ & $22.4 \pm 3.0^{*}$ & $340 \pm 14^{*}$ & $220 \pm 19$ \\
\hline \multicolumn{5}{|l|}{ Plus cholesterol $(0.12 \%)$} \\
\hline and olive oil (10\%) & $51.7 \pm 6^{*}$ & $21.4 \pm 1.4^{*}$ & $471 \pm 44^{*}$ & $248 \pm 25$ \\
\hline
\end{tabular}

For $30 \mathrm{~d}$, a group of male hamsters was fed plain rodent diet low in cholesterol $(0.02 \%)$ and total lipid (5.0\%) content. A second group of animals was fed this same diet to which was added $0.12 \%$ cholesterol, while a third group (control diet) was fed this diet containing $0.12 \%$ cholesterol and $10 \%$ olive oil. At the end of the feeding period the rates of receptor-dependent and receptor-independent LDL-cholesterol transport into the liver and remaining organs of the body were measured in vivo, and these values were used to calculate the absolute rates of maximal receptordependent transport $\left(J^{m}\right)$ in the liver and the LDL-cholesterol production rate in the whole animal $\left(J_{t}\right)$. Both of these rates were then normalized to a constant 100-g body weight, and so are expressed as the $\mu \mathrm{g}$ of LDL-cholesterol transported into the liver and produced by the whole animal per $\mathrm{h}$ per $100 \mathrm{~g}$ animal. In addition, the concentration of LDL-cholesterol in the plasma $(\mathrm{mg} / \mathrm{dl})$ and total cholesterol in the liver $(\mathrm{mg} / \mathrm{g})$ of each animal was also determined. Each value represents the mean \pm 1 SEM for data from 6 animals. ${ }^{*}$ Value is significantly different $(P<0.05)$ from the corresponding value found in the animals fed plain diet. 
steady-state LDL-cholesterol concentration averaged only $25.0 \mathrm{mg} / \mathrm{dl}$. When $0.12 \%$ cholesterol was added to this diet, the pool of total cholesterol in the liver increased from 2.4 to 22.4 $\mathrm{mg} / \mathrm{g}$, while $J^{\mathrm{m}}$ declined to $52 \%(340 \mu \mathrm{g} / \mathrm{h})$, and $J_{\mathrm{t}}$ increased to $133 \%(220 \mu \mathrm{g} / \mathrm{h})$ of the respective values found with plain diet alone. These changes raised the steady-state plasma LDL-cholesterol level to $59.0 \mathrm{mg} / \mathrm{dl}$. Finally, when $10 \%$ olive oil was added to this cholesterol-containing diet, there was partial restoration of $J^{\mathrm{m}}(72 \%)$, essentially no change in $J_{\mathrm{t}}(149 \%)$ or hepatic cholesterol concentration $(21.4 \mathrm{mg} / \mathrm{g})$, and a small decrease in the mean plasma LDL-cholesterol concentration $(51.7 \mathrm{mg} / \mathrm{dl})$. These various changes were all anticipated and were consistent with previous quantitative data on the effects of dietary cholesterol and triacylglycerols containing mixtures of unsaturated fatty acids $(7,10,12)$.

With these absolute values for the parameters of LDL metabolism defined in the animals receiving the control diet, similar measurements were next made in groups of 18 hamsters eating the experimental diets containing the various saturated fatty acids. As shown in Fig. 2, intake of triacylglycerol containing the 6:0, 8:0, and 10:0 fatty acids had no significant effect on the plasma LDL-cholesterol concentration $(A)$, hepatic receptor activity $(B)$ or LDL-cholesterol production rate $(C)$ when compared to the control diet. Furthermore, as summarized in Fig. 3, these fatty acids also did not alter the concentration of cholesterol in the liver. However, when either the 12:0, 14:0, or 16:0 compounds was fed; there was significant suppression of hepatic receptor activity $(B)$, a reciprocal increase in the relative production rate $(C)$, and a near doubling of the LDL-cholesterol concentration in the plasma $(A)$. In addition, the he-

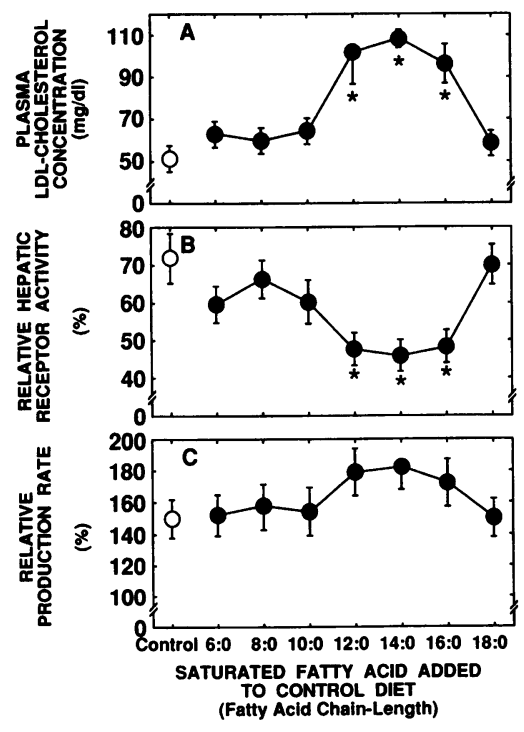

Figure 2. Maximal receptor-dependent LDL-cholesterol transport in the liver, and the LDL-cholesterol production rate in animals fed various triacylglycerols. For $30 \mathrm{~d}$, groups of animals were fed either the control diet containing $0.12 \%$ cholesterol and $10 \%$ olive oil, or the experimental diets containing an additional $10 \%$ triacylglycerol made up of the fatty acids $6: 0$ through 18:0. At the end of the feeding period, the plasma LDL-cholesterol concentration was measured $(A)$, and both the maximal rate of LDL-cholesterol uptake into the liver $\left(J^{\mathrm{m}}\right)$ and the whole-animal LDL-cholesterol production rate $\left(J_{t}\right)$ were measured and are shown in $B$ and $C$, respectively. These latter values are expressed as percentages of the absolute values for $J^{m}$ and $J_{t}$ found in animals fed only plain diet, and listed in Table III. Each value represents the mean \pm 1 SEM for 18 animals. *Indicates the value is significantly different $(P<0.05)$ from the corresponding value found in the animals fed the control diet.

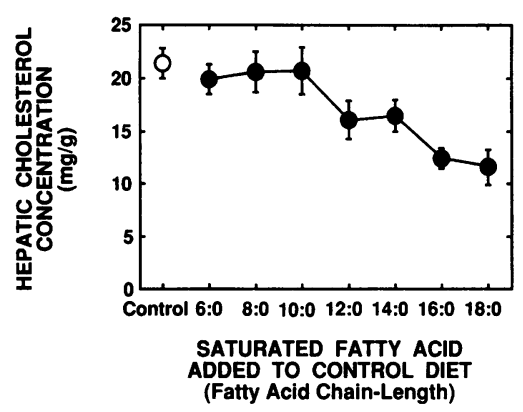

Figure 3. Hepatic cholesterol concentration in animals fed different triacylglycerols. For 30 d, animals were fed either the control diet or the experimental diets containing the various triacylglycerols. At the end of this time, hepatic total cholesterol concentrations were measured. Each value represents the mean \pm 1 SEM for 18 animals.

patic concentration of cholesterol was lowered as the liver became enriched with these particular fatty acids (Fig. 3). While these changes in receptor activity and plasma cholesterol concentration were all significantly different from those found in the control animals, there were no significant differences in the values found among these three saturated fatty acids. Furthermore, when the absolute values for $J^{\mathrm{m}}$ and $J_{\mathrm{t}}$ found after feeding the 12:0,14:0, and 16:0 compounds were substituted into Eq. 2 (Methods), the predicted values for the plasma cholesterol level, $\mathrm{C}_{1}$, were equal to those values observed experimentally (Fig. 2). Thus, these three saturated fatty acids significantly altered the parameters of LDL transport and production, and these changes alone were sufficient to account for the near doubling of the LDL-cholesterol concentration observed in these experiments.

The results obtained when the remaining long-chain saturated fatty acid, the 18:0 compound, was fed, were very different. Even though this fatty acid reduced the level of cholesterol in the liver to the same degree as did the 16:0 compound (Fig. 3 ), it did not alter either the relative receptor activity (Fig. $2 B$ ) or production rate $(C)$ and, as a consequence, it had no effect on the plasma LDL-cholesterol level $(A)$. Like the 6:0, 8:0, and 10:0 compounds, the 18:0 fatty acid apparently exerts no metabolic regulation in the liver on the transport parameters that dictate plasma cholesterol levels.

While these results are all consistent with an intrahepatic effect of these fatty acids, one additional experiment was done to rule out the possibility that this regulation was, in fact, mediated through a change in net sterol delivery from the intestine or peripheral organs to the liver. Using animals fed experimental diets containing either the $16: 0$ or 18:0 fatty acids, rates of cholesterol synthesis were measured in vivo in the small intestine, liver, and remaining organs of the carcass. As shown in Table IV, in animals receiving the control diet, the rate of whole animal sterol synthesis equaled $4,861 \mathrm{nmol} / \mathrm{h}$, and $1.4 \%$ of this occurred in the liver, $12 \%$ in the small intestine, and $87 \%$ in the remaining tissues of the body. It should be noted that hepatic sterol synthesis in the liver of animals receiving plain diet equals $\sim 300 \mathrm{nmol} / \mathrm{h}$. The lower rate found in this study reflects suppression of hepatic synthesis by the small amount of cholesterol present in the control diet. When either the $16: 0$ or 18:0 compound was fed, there was a small, but significant, increase in the rate of hepatic sterol synthesis with both fatty acids, but no differences were found in the rates of sterol synthe- 
Table IV. Cholesterol Synthesis In Vivo in Liver, Small Intestine and Remaining Carcass in Animals Fed Triacylglycerols Containing Either the Saturated Fatty Acid 16:0 or 18:0

\begin{tabular}{ccccc}
\hline \multirow{2}{*}{$\begin{array}{c}\text { Saturated } \\
\text { fatty acid } \\
\text { added to } \\
\text { control diet }\end{array}$} & Liver & Small intestine & Carcass & Whole animal \\
\cline { 2 - 5 } & \multicolumn{5}{c}{ Cholesterol synthesis in vivo } \\
\hline \multicolumn{5}{c}{ nmol/h per organ or animal } \\
Control & $69 \pm 8$ & $581 \pm 102$ & $4,211 \pm 247$ & $4,861 \pm 330$ \\
$16: 0$ & $110 \pm 10^{*}$ & $581 \pm 21$ & $4,640 \pm 196$ & $5,331 \pm 209$ \\
$18: 0$ & $142 \pm 17^{*}$ & $698 \pm 61$ & $4,520 \pm 241$ & $5,360 \pm 295$ \\
& & & & \\
\end{tabular}

For $30 \mathrm{~d}$ groups of animals were fed either the control diet alone or the control diet to which was added $10 \%$ triacylglycerol that contained either the $16: 0$ or 18:0 fatty acid. At the end of this feeding period, cholesterol synthesis was measured in vivo in various tissues. Each value represents the mean \pm 1 SEM for 6 animals. ${ }^{*}$ Value is significantly different $(P<0.05)$ from the control value.

sis measured in the small intestine and remaining tissues of the carcass. Thus, the differential effects of the 16:0 and 18:0 fatty acids on LDL metabolism could not be attributed to differences in net cholesterol delivery to the regulatory pool in the liver brought about by differential effects of these two lipids on de novo cholesterol synthesis in the intestine, carcass, or even the liver itself.

\section{Discussion}

The concentration of circulating LDL cholesterol is, for practical purposes, determined by the rate of LDL-cholesterol formation relative to the rate of receptor-dependent LDL removal from the plasma (27). Both of these processes, in turn, are largely dictated by events taking place in the liver. This organ, for example, is the principal location of receptor activity in the body $(8,9,22,23,29)$. Furthermore, while LDL itself is probably not secreted by the liver (30), this organ nevertheless also plays a critical role in determining the LDL-cholesterol production rate. Partially metabolized very low density lipoprotein particles are apparently normally cleared from the plasma by hepatic LDL receptors, and so are not converted to LDL (3133). Thus, there is usually a reciprocal relationship observed between $J^{\mathrm{m}}$ and $J_{\mathrm{t}}$ (e.g., Fig. 2), regardless of whether receptor activity is altered through genetic or dietary mechanisms $(7,9$, $10,34)$. The liver also plays a central role in the metabolism of dietary lipids, including both cholesterol and fatty acids, and it is now apparent that the inflow of these lipids leads to complex changes in both $J^{\mathrm{m}}$ and $J_{\mathrm{t}}$ which, in turn, bring about significant alterations in steady-state LDL-cholesterol levels. How these changes are mediated at the cellular level, however, is very poorly understood.

The most dramatic changes in LDL-cholesterol levels are seen when saturated fatty acids are fed in conjunction with cholesterol $(11,35,36)$. In the hamster, for example, the plasma LDL-cholesterol level is elevated over threefold when such triacylglycerols are fed along with small quantities of cholesterol, as compared to feeding the same quantity of choles- terol alone. These changes result from significant suppression of $J^{\mathrm{m}}$ coupled with a near doubling of $J_{\mathrm{t}}(12)$. One of the critical questions addressed in the present study is which of the saturated fatty acids is responsible for these changes.

There are known to be significant differences in the manner in which different fatty acids are handled by the body. Those saturated fatty acids of short and medium chain length are fairly hydrophilic, and so are rapidly absorbed across the intestinal brush border without the intervention of micellar solubilization $(37,38)$. Once absorbed, these compounds are not reesterified and incorporated into the nascent chylomicron but, rather, pass directly into the portal circulation from which they are extracted by the liver. Within the liver, these fatty acids are able to enter the mitochondrial compartment, without using the carnitine transfer process (39), where they are activated by medium chain and long chain acyl-CoA synthetases and oxidized to acetyl CoA (40). This pool of acetyl-CoA is then available for the various oxidative and synthetic processes normally carried out by the liver cell. Given this information, it is not surprising that the 6:0, 8:0, and 10:0 fatty acids cannot be detected in the lipids of either the peripheral adipose tissue or liver (Table I), even after feeding these three triacylglycerols for $30 \mathrm{~d}$. Furthermore, even though these compounds undoubtedly expand the intrahepatic acetyl-CoA pool (41), there are no significant changes in the relative abundance of any of the longer chain-length fatty acids (Tables I and II), nor are there any alterations in $J^{\mathrm{m}}, J_{\mathrm{t}}$, or the plasma LDL-cholesterol level (Fig. 2). Thus, the delivery of large quantities of two-carbon units to the liver in this form does not alter any parameter of LDL metabolism.

The saturated fatty acids of longer chain length are more hydrophobic and require micellar solubilization within the intestinal lumen for effective absorption $(37,38)$. Within the epithelial cell, these compounds are reesterified, and the triacylglycerol is then incorporated into chylomicrons and delivered to peripheral adipose and muscle tissues. A portion of the triacylglycerol is retained within the chylomicron remnants, and is subsequently taken up by the liver. It is also not surprising, therefore, that the pools of fatty acid found in the adipocyte, muscle cell, and hepatocyte become relatively enriched with the $12: 0,14: 0,16: 0$, or 18:0 compounds when each of these respective acids is fed in the diet for $30 \mathrm{~d}$ (Table I). Furthermore, the liver is known to contain enzyme systems capable of elongating and desaturating these specific fatty acids (42). This very likely accounts for the observation that the $16: 0$ fatty acid becomes enriched in this organ after feeding the 12:0 and 14:0, as well as the $16: 0$, fatty acids. Notably, however, the abundance of the 18:0 compound becomes increased only after feeding the 18:0 fatty acid, and furthermore, the levels of the 18:1 fatty acid are not increased, even after feeding the 18:0 compound for $30 \mathrm{~d}$. Thus, even though the lipids reaching the liver were being constantly removed, through oxidation and secretion of very low density lipoproteins, in the steady state feeding specific fatty acids results in characteristic changes in the abundance of these compounds in the whole organ (Table I), and in the major lipid classes of that organ (Table II).

In the case of the 12:0,14:0, and 16:0 compounds, the accumulation of these fatty acids is associated with suppression of hepatic receptor activity, reciprocal increases in the mean LDL-cholesterol production rate, and a marked increase in the LDL-cholesterol level in the plasma (Fig. 2). In contrast, accu- 
mulation of the 18:0 fatty acid is not associated with any of these changes, even though it becomes enriched in the liver to the same degree as the 16:0 compound (Table I). Essentially identical results have been reported in man, at least with respect to changes in the plasma LDL-cholesterol level which was elevated $22 \%$ after feeding a diet enriched with the 16:0 fatty acid, but not after feeding the 18:0 compound, for 3 wk (43). Thus, these results appear to explain why commercial saturated oils such as hydrogenated coconut oil and butter fat (rich in the 12:0, 14:0, and 16:0 fatty acids) are so potent in raising the plasma LDL-cholesterol level, while other equally saturated products such as cocoa butter (rich in the 18:0 fatty acid) are much less active in this regard. Such differences have been observed in both animal studies and in investigations in man $(7,44,45)$. Clearly, the general recommendation against use of saturated fatty acids in the diet should apply only to the $12: 0,14: 0$, and 16:0 compounds, and not to the 18:0 fatty acid or those with chain lengths of 10 or less carbon atoms.

The manner in which these effects of specific fatty acids are articulated in the liver cell is of considerable theoretical importance. In the male hamsters used in these studies, as in other animals and probably man, receptor activity is maximal and the production rate is minimal under conditions where there is no lipid in the diet (Table III). The effect on the plasma cholesterol concentration of adding triacylglycerol to such diets is clearly dependent upon the simultaneous addition of cholesterol. In the absence of dietary sterol, for example, $20 \%$ hydrogenated coconut oil raises the plasma LDL-cholesterol level by only $16 \mathrm{mg} / \mathrm{dl}$, but this incremental effect increases to 46,93 , and $112 \mathrm{mg} / \mathrm{dl}$ under circumstances where the level of dietary cholesterol is increased to $0.06,0.12$, and $0.24 \%$, respectively (10). Thus, one possibility is that the differential effects of these longer chain-length saturated fatty acids can be explained in terms of the varying effects of these compounds on net cholesterol balance across the liver. However, the data do not support this possibility. The absolute rates of cholesterol synthesis were essentially identical in the intestine and other extrahepatic tissues in animals fed the control diet or the diets containing the 16:0 and 18:0 fatty acids (Table IV). Furthermore, there was no difference in either the rate of hepatic cholesterol synthesis ( Table IV) or the hepatic cholesterol pool (Fig. 3) in the animals fed the 16:0 and 18:0 compounds. If the failure of the 18:0 fatty acid to suppress $J^{\mathrm{m}}$ was due to a reduction in net cholesterol movement across the liver, then, invariably, there would have been a marked decrease in the sterol pool in the liver accompanied by a significant increase in the rate of hepatic cholesterol synthesis. Neither of these events was observed.

A second possibility is that the presence of these saturated fatty acids within the liver alters the quantitative relationships between the putative regulatory pool of unesterified cholesterol in the cell and the transcriptional factors that interact with the sterol regulatory elements of the LDL receptor gene (14-16). It is known, for example, that feeding triacylglycerols containing only the $18: 1$ or $18: 2$ fatty acids increases the size of the cholesteryl ester pool in the liver, and is associated with an increase in receptor activity (unpublished observations from this laboratory), while feeding saturated fatty acids lowers the pool of cholesterol in the liver cell and suppresses $J^{m}$. These observations would be consistent with the view that those fatty acids that are good substrates for cholesteryl ester formation lower the effective concentration of free cholesterol in the putative regulatory pool of the cell, while those that are not, e.g., the saturated fatty acids, increase this level and so suppress receptor activity. While this scenario may well be true for groups of different fatty acids in general, it cannot explain the difference observed between the 16:0 and 18:0 fatty acids. Both of these compounds became significantly enriched in the cholesteryl ester pool (Table II) and reduced the content of cholesterol in the liver (Fig. 3), yet only the 16:0 fatty acid suppressed receptor activity.

There is a third, and clearly speculative, possibility. When the 12:0,14:0, or 16:0 fatty acids were fed, the sum of the abundances of the 14:0 and 16:0 fatty acids always became elevated to about $25 \%$ (Table I), and all three of these compounds suppressed $J^{\mathrm{m}}$ equally (Fig. 2). The 14:0 and 16:0 compounds are now known to be involved in the myristoylation and palmitoylation, respectively, of a variety of proteins, both membrane bound and soluble, that are involved in signal transduction, regulation of a variety of metabolic pathways, and, possibly, processes of membrane fusion (46-48). It is conceivable, therefore, that enrichment of the hepatic content of the 14:0 and 16:0 compounds may alter receptor-dependent LDL transport only indirectly through some process that does not necessarily involve changes in either the external or internal pools of cellular cholesterol.

Thus, these studies demonstrate that the dietary saturated fatty acids 12:0, 14:0, and 16:0 accumulate in the liver and suppress hepatic LDL receptor activity, enhance the rate of LDL-cholesterol formation, and markedly elevate the plasma LDL-cholesterol level. Future studies will have to more precisely define why these particular compounds, and not the other saturated fatty acids, are able to alter the intracellular regulatory events that dictate membrane receptor-dependent LDL transport in the liver. Nevertheless, these investigations do emphasize that only these three saturated fatty acids have detrimental effects on the plasma LDL-cholesterol level.

\section{Acknowledgments}

The authors thank Anne Bell, Mark Herndon and Jody Houston for their excellent technical help, and Imogene Robison for preparation of the manuscript.

This work was supported by National Institutes of Health Research Grant HL-09610, and by a grant from the Moss Heart Fund. In addition, Dr. Woollett was supported by a grant from the National Live Stock and Meat Board, and the Institute of Shortening and Edible Oils, Inc., provided additional funding to purchase the large quantities of pure triacylglycerols required for these studies.

\section{References}

1. Spady, D. K., S. D. Turley, and J. M. Dietschy. 1983. Dissociation of hepatic cholesterol synthesis from hepatic low-density lipoprotein uptake and biliary cholesterol saturation in female and male hamsters of different ages. Biochim. Biophys. Acta. 753:381-392.

2. Spady, D. K., S. D. Turley, and J. M. Dietschy. 1985. Rates of low density lipoprotein uptake and cholesterol synthesis are regulated independently in the liver. J. Lipid Res. 26:465-472.

3. Dietschy, J. M., T. Kita, K. E. Suckling, J. L. Goldstein, and M. S. Brown. 1983. Cholesterol synthesis in vivo and in vitro in the WHHL rabbit, an animal with defective low density lipoprotein receptors. J. Lipid Res. 24:469-480.

4. Connor, W. E., M. T. Cerqueira, R. W. Connor, R. B. Wallace, M. R. Malinow, and H. R. Casdorph. 1978. The plasma lipids, lipoproteins, and diet of the Tarahumara Indians of Mexico. Am. J. Clin. Nutr. 31:1131-1142.

5. Crook, D., K. H. Weisgraber, J. K. Boyles, and R. W. Mahley. 1990. Isolation and characterization of plasma lipoproteins of common marmoset monkey. Comparison of effects of control and atherogenic diets. Arteriosclerosis. 10:633-647. 
6. Dietschy, J. M., D. K. Spady, and J. B. Meddings. 1988. A quantitative approach to low density lipoprotein metabolism in man and in various experimental animals. In Hyperlipidaemia and Atherosclerosis. K. E. Suckling and P. H. E. Groot, editors. Academic Press, London. 17-32.

7. Woollett, L. A., D. K. Spady, and J. M. Dietschy. 1989. Mechanisms by which saturated triacylglycerols elevate the plasma low density lipoprotein-cholesterol concentration in hamsters. Differential effects of fatty acid chain length. J. Clin. Invest. 84:119-128.

8. Spady, D. K., J. B. Meddings, and J. M. Dietschy. 1986. Kinetic constants for receptor-dependent and receptor-independent low density lipoprotein transport in the tissues of the rat and hamster. J. Clin. Invest. 77:1474-1481.

9. Spady, D. K., M. Huettinger, D. W. Bilheimer, and J. M. Dietschy. 1987. Role of receptor-independent low density lipoprotein transport in the maintenance of tissue cholesterol balance in the normal and WHHL rabbit. J. Lipid Res. 28:32-41.

10. Spady, D. K., and J. M. Dietschy. 1988. Interaction of dietary cholesterol and triglycerides in the regulation of hepatic low density lipoprotein transport in the hamster. J. Clin. Invest. 81:300-309.

11. Spady, D. K., and J. M. Dietschy. 1985. Dietary saturated triacylglycerols suppress hepatic low density lipoprotein receptor activity in the hamster. Proc. Natl. Acad. Sci. USA. 82:4526-4530.

12. Woollett, L. A., D. K. Spady, and J. M. Dietschy. 1992. Saturated and unsaturated fatty acids independently regulate low density lipoprotein receptor activity and production rate. J. Lipid Res. 33:77-88.

13. Südhof, T. C., D. W. Russell, M. S. Brown, and J. L. Goldstein. 1987. 41 bp element from LDL receptor gene confers end-product repression by sterols when inserted into viral TK promoter. Cell. 48:1061-1069.

14. Metherall, J. E., J. L. Goldstein, K. L. Luskey, and M. S. Brown. 1989. Loss of transcriptional repression of three sterol-regulated genes in mutant hamster cells. J. Biol. Chem. 264:15634-15641.

15. Smith, J. R., T. F. Osborne, J. L. Goldstein, and M. S. Brown. 1990. Identification of nucleotides responsible for enhancer activity of sterol regulatory element in low density lipoprotein receptor gene. J. Biol. Chem. 265:2306-2310.

16. Dawson, P. A., J. E. Metherall, N. D. Ridgway, M. S. Brown, and J. L. Goldstein. 1991. Genetic distinction between sterol-mediated transcriptional and posttranscriptional control of 3-hydroxy-3-methylglutaryl-coenzyme A reductase. J. Biol. Chem. 266:9128-9134.

17. Lepage, G., and C. C. Roy. 1986. Direct transesterification of all classes of lipids in a one-step reaction. J. Lipid Res. 27:114-120.

18. Tonks, D. B. 1967. The estimation of cholesterol in serum: A classification and critical review of methods. Clin. Biochem. 1:12-29.

19. Pittman, R. C., T. E. Carew, C. K. Glass, S. R. Green, C. A. Taylor, Jr., and A. D. Attie. 1983. A radioiodinated, intracellularly trapped ligand for determining the sites of plasma protein degradation in vivo. Biochem. J. 212:791-800.

20. McFarlane, A. S. 1958. Efficient trace-labelling of proteins with iodine Nature (Lond.). 182:53.

21. Bilheimer, D. W., S. Eisenberg, and R. I. Levy. 1972. The metabolism of very low density lipoprotein proteins. I. Preliminary in vitro and in vivo observations. Biochim. Biophys. Acta. 260:212-221.

22. Spady, D. K., D. W. Bilheimer, and J. M. Dietschy. 1983. Rates of receptor-dependent and -independent low density lipoprotein uptake in the hamster. Proc. Natl. Acad. Sci. USA. 80:3499-3503.

23. Spady, D. K., S. D. Turley, and J. M. Dietschy. 1985. Receptor-independent low density lipoprotein transport in the rat in vivo. Quantitation, characterization, and metabolic consequences. J. Clin. Invest. 76:1113-1122.

24. Jeske, D. J., and J. M. Dietschy. 1980. Regulation of rates of cholestero synthesis in vivo in the liver and carcass of the rat measured using $\left[{ }^{3} \mathrm{H}\right]$ water. $J$. Lipid Res. 21:364-376.

25. Turley, S. D., J. M. Andersen, and J. M. Dietschy. 1981. Rates of sterol synthesis and uptake in the major organs of the rat in vivo. J. Lipid Res. 22:551569.

26. Dietschy, J. M., and D. K. Spady. 1984. Measurement of rates of cholesterol synthesis using tritiated water. J. Lipid Res. 25:1469-1476.
27. Meddings, J. B., and J. M. Dietschy. 1987. Regulation of plasma low density lipoprotein levels: New strategies for drug design. Prog. Clin. Biochem. Med. 5:1-24.

28. Snedecor, G. W., and W. G. Cochran. 1971. Statistical Methods. 6th Edition. Iowa State University Press, Ames, IA. 534 pp.

29. Bilheimer, D. W., J. L. Goldstein, S. M. Grundy, T. E. Starzl, and M. S. Brown. 1984. Liver transplantation to provide low-density-lipoprotein receptors and lower plasma cholesterol in a child with homozygous familial hypercholesterolemia. N. Engl. J. Med. 311:1658-1664.

30. Shames, D. M., and R. J. Havel. 1991. De novo production of low density lipoproteins: fact or fancy. J. Lipid Res. 32:1099-1112.

31. Kita, T., M. S. Brown, D. W. Bilheimer, and J. L. Goldstein. 1982. Delayed clearance of very low density and intermediate density lipoproteins with enhanced conversion to low density lipoprotein in WHHL rabbits. Proc. Natl. Acad. Sci. USA. 79:5693-5697.

32. Hornick, C. A., T. Kita, R. L. Hamilton, J. P. Kane, and R. J. Havel. 1983. Secretion of lipoproteins from the liver of normal and Watanabe heritable hyperlipidemic rabbits. Proc. Natl. Acad. Sci. USA. 80:6096-6100.

33. Yamada, N., D. M. Shames, J. B. Stoudemire, and R. J. Havel. 1986. Metabolism of lipoproteins containing apolipoprotein B-100 in blood plasma of rabbits: Heterogeneity related to the presence of apolipoprotein E. Proc. Natl. Acad. Sci. USA. 83:3479-3483.

34. Bilheimer, D. W., N. J. Stone, and S. M. Grundy. 1979. Metabolic studies in familial hypercholesterolemia. Evidence for a gene-dosage effect in vivo. $J$ Clin. Invest. 64:524-533.

35. Mattson, F. H., and S. M. Grundy. 1985. Comparison of effects of dietary saturated, monounsaturated, and polyunsaturated fatty acids on plasma lipids and lipoproteins in man. J. Lipid Res. 26:194-202.

36. Johnson, F. L., R. W. St. Clair, and L. L. Rudel. 1985. Effects of the degree of saturation of dietary fat on the hepatic production of lipoproteins in the African green monkey. J. Lipid Res. 26:403-417.

37. Sallee, V. L., and J. M. Dietschy. 1973. Determinants of intestinal mucosal uptake of short- and medium-chain fatty acids and alcohols. J. Lipid Res. 14:475-484.

38. Westergaard, H., and J. M. Dietschy. 1976. The mechanism whereby bile acid micelles increase the rate of fatty acid and cholesterol uptake into the intestinal mucosal cell. J. Clin. Invest. 58:97-108.

39. McGarry, J. D., and D. W. Foster. 1980. Regulation of hepatic fatty acid oxidation and ketone body production. Annu. Rev. Biochem. 49:395-420.

40. Schulz, H. 1991. Beta oxidation of fatty acids. Biochim. Biophys. Acta. 1081:109-120.

41. Dietschy, J. M., and M. S. Brown. 1974. Effect of alterations of the specific activity of the intracellular acetyl CoA pool on apparent rates of hepatic cholesterogenesis. J. Lipid Res. 15:508-516.

42. Cook, H. W. 1985. Fatty acid desaturation and chain elongation in eucaryotes. In Biochemistry of Lipids and Membranes. D. E. Vance and J. E. Vance, editors. The Benjamin/Cummings Publishing Company, Inc., Menlo Park, CA. 181-212.

43. Bonanome, A., and S. M. Grundy. 1988. Effect of dietary stearic acid on plasma cholesterol and lipoprotein levels. N. Engl. J. Med. 318:1244-1248.

44. Ahrens, E. H., W. Insull, R. Blomstrand, J. Hirsch, T. T. Tsaltas, and M. L. Peterson. 1957. The influence of dietary fats on serum-lipid levels in man. Lancet i:943-953.

45. Hegsted, D. M., R. B. McGandy, M. L. Myers, and F. J. Stare. 1965. Quantitative effects of dietary fat on serum cholesterol in man. Am. J. Clin. Nutr. 17:281-295.

46. Mcllhinney, R. A. 1990. The fats of life: the importance and function of protein acylation. TIBS (Trends Biochem. Sci.) 387-391.

47. Takeda, A., and A. L. Maizel. 1990. An unusual form of lipid linkage to the CD45 peptide. Science (Wash. DC). 250:676-679.

48. Ruff, P., D. W. Speicher, and A. Husain-Chishti. 1991. Molecular identifcation of a major palmitoylated erythrocyte membrane protein containing the src homology 3 motif. Proc. Natl. Acad. Sci. USA. 88:6595-6599. 